\title{
Nuclear DNA content and p53 overexpression in stage I squamous cell carcinoma of the tongue compared with advanced tongue carcinomas
}

\author{
A Högmo, R Kuylenstierna, J Lindholm, A Nathansson, G Auer, E Munck-Wikland
}

\begin{abstract}
Aims-To evaluate the predictive value of the nuclear DNA content (image cytometry) and p53 overexpression (immunohistochemistry using antibody CM-1) in uniformly treated stage I carcinomas of the mobile tongue. Also, to compare stage I carcinomas with advanced tongue carcinomas (stages II-IV).

Methods-Archival formalin fixed, paraffin wax embedded tumour specimens from 54 patients with stage I squamous cell carcinoma and 37 patients with advanced squamous cell carcinoma were analysed. Mean follow up time of the stage I carcinomas was 71 months (median, 62.5; range, 6-175).
\end{abstract}

Results-Twenty three patients (stage I) had recurring disease: 10 had local recurrence (in the tongue) and 13 had regional recurrence (cervical metastases). Locally recurring stage I carcinomas had a more pronounced DNA deviation than the other stage I carcinomas and this degree of deviation was comparable with the DNA content of advanced carcinomas. Stage I carcinomas that developed regional recurrences overexpressed p53 more frequently. In Cox multivariate regression analysis of time to recurrence, DNA deviation was a significant parameter in tumours that recurred locally $(p=0.032)$. p53 overexpression was the only parameter close to significance for regional

Department of Oto-Rhino-Laryngology, Head and Neck Surgery, Karolinska Hospital, S-171 76 Stockholm, Sweden A Högmo

R Kuylenstierna

E Munck-Wikland

Department of Tumor Pathology, Karolinska Hospital

J Lindholm

G Auer

recurrence $(p=0.065)$.

Conclusions-Nuclear DNA content and p53 immunostaining are of value for the prediction of recurrence of stage I squamous cell carcinomas of the mobile tongue. Stage I tongue carcinomas that are prone to local recurrence show the same DNA content as do advanced tongue carcinomas.

(f Clin Pathol: Mol Pathol 1998;51:268-272)

Keywords: squamous cell carcinoma; DNA; protein p53

Department of

Oto-Rhino-Laryngology, Carcinoma of the mobile part of the tongue is Head and Neck Surgery, Söder Hospital, S-118 83

Stockholm, Sweden

A Nathansson

Correspondence to: Dr Högmo.

Accepted for publication 16 June 1998 the mobile tongue are treated with wedge excision only and, in general, more advanced tumours (stages II-IV) are treated with preoperative irradiation followed by more extensive surgery. However, among stage I tongue carcinomas there is a subgroup of tumours that is prone to local and/or regional recurrence. If this more aggressive behaviour could be predicted, this subgroup could be subjected to extended treatment, thus sparing patients with less aggressive carcinomas the morbidity caused by such treatment. The problem is even more urgent because recent epidemiological studies in Sweden show an increased incidence of tongue cancers among people less than 40 years of age, yet there has been no improvement in treatment results for many decades. ${ }^{1}$

Many attempts have been made to predict the outcome for tongue carcinomas through histopathological studies and molecular biology. ${ }^{2-6}$ The degree of DNA deviation in a tumour cell population reflects its genetic instability but DNA analysis, by flow or image cytometry, has yielded varying results as a predictive tool when applied to head and neck carcinomas. $^{7-9}$

Mutation of the p53 tumour suppressor gene usually results in a gene product consisting of a defective $\mathrm{p} 53$ protein with a prolonged half life, which enables detection through immunohistochemical methods. For head and neck cancers, p53 immunoreactivity has been shown to be a poor predictive value, in contrast to studies involving colonic or breast carcinomas. However, p53 studies on head and neck cancers have to a great extent been performed on material from tumours at different sites and at different stages, where biological parameters might have a different impact. ${ }^{70-13}$ p53 is also receiving further attention as an approach for gene therapy. ${ }^{14}$

The aim of this study was to evaluate the importance of nuclear DNA content and p53 immunostaining in predicting the risk of recurrence of uniformly treated stage I carcinomas of the mobile tongue. A secondary aim was to compare these biological properties of small carcinomas to more advanced carcinomas (stages II-IV) of the mobile tongue.

\section{Methods}

PATIENTS

Fifty six consecutive patients were treated for squamous cell carcinoma of the mobile tongue at the department Oto-Rhino-Laryngology of Karolinska Hospital in Stockholm, Sweden, from January 1980 to November 1990. Nineteen of these patients presented with tumours classified as stage I (UICC; 1987). These 19 patients were added to 41 patients suffering from stage I tongue carcinomas collected during a multicentre study in Sweden from 1974 


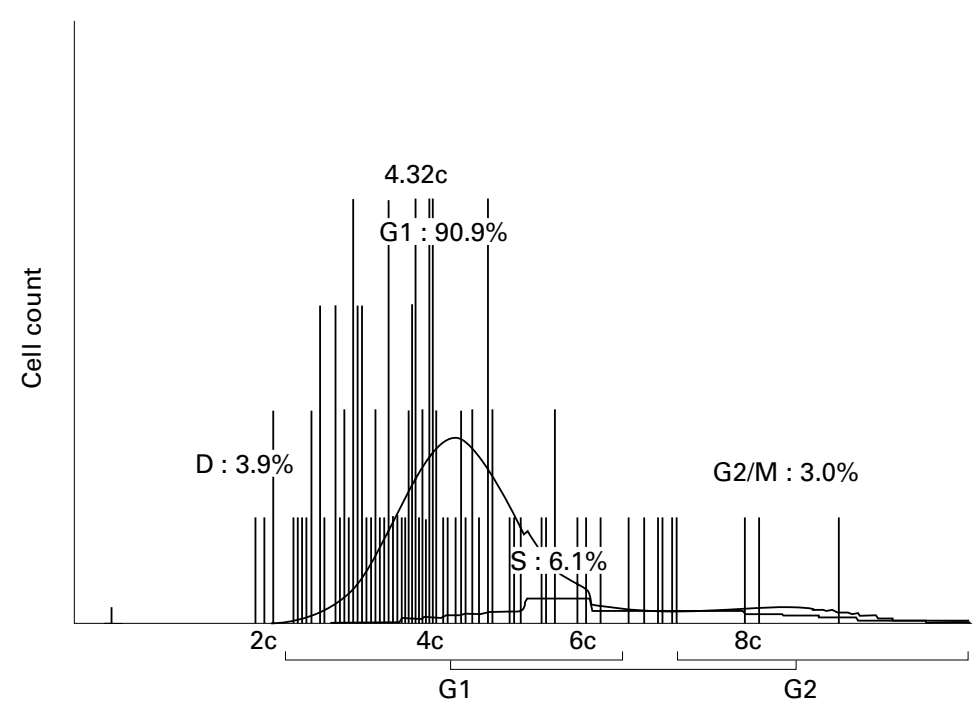

Figure 1 Example of DNA histogram for one specimen. Nuclear DNA content: $>5 c E R=18.4 \%$. third layer of $\mathrm{ABC}$ Vectastain kit elite (Vector Laboratories, California, USA) and diaminobenzidine (DAB) was added. Finally, a weak counterstain was used to visualise the nuclei.

DNA MEASUREMENT

For the quantitative DNA analysis, a densitometric device, the Ahrens image analysis system (Bargtheide, Hamburg, Germany) was used (Microscope NIKON, plan objective 40/0.95, TV based, video CCD camera).

The DNA content of 100 cell nuclei/ specimen was registered. Lymphocytes were used as control cells to establish the normal diploid (2c) value. ${ }^{16}$

DNA content up to $4 \mathrm{c}$ is seen in premitotic normal cells, but DNA values exceeding 5c are found only rarely in normal epithelial cells. The percentage of cells with a nuclear DNA content of $>5 c$ ( $\% 5 c$ exceeding rate; $\% 5 c E R)$ of each specimen was calculated (fig 1).

p53 IMMUNOSTAINING

The specimens were considered to be p53 positive (+) when a distinct brown staining, confined to the nuclei, could be seen in at least $1 \%$ of the cells.

For the p53 analysis, the MDA 231 breast cancer cell line was used as an external positive control. Non-tumour cells were used as an internal negative control.

\section{STATISTICAL METHODS}

The $\chi^{2}$ test was used to determine the differences in distribution between groups. Differences between means were determined with the Student's $t$ test, and all $\mathrm{p}$ values are two tailed. Four patients who died from intercurrent disease during the follow up were excluded from these tests $(n=50)$. For univariate analysis of categorical data (p53 and grade of differentiation) in relation to time to recurrence, the log rank test was applied, whereas Cox regression analysis was used for univariate evaluation of the importance of $\% 5 \mathrm{cER}$ (continous variable) $(\mathrm{n}=54)$.

Cox multivariate regression analysis was applied to evaluate which of the factors had the greatest influence on recurrence and survival. The level of statistical significance was set at $\mathrm{p}=0.05$.

\section{Results}

Four out of 54 patients died from intercurrent disease during follow up (after 6, 15, 17, and 31 months). For each of the following analyses the number of included patients is stated.

\section{RECURRENCE}

Twenty three of the 54 patients with stage I tongue carcinoma had a recurrence during the follow up time. Ten patients had local recurrence in the tongue (10 of 54) and 13 patients had regional recurrence (cervical metastases; 13 of 54).

NUCLEAR DNA CONTENT

Table 1 and fig 2 give the result for nuclear DNA content. Stage I tumours that later recurred, locally or regionally, displayed a 
Table 1 Analysis of nuclear DNA content (\%5cER) and immunohistochemistry (IHC) for $p 53$

\begin{tabular}{|c|c|c|c|c|c|c|c|}
\hline & \multicolumn{4}{|c|}{$\% 5 c E R$} & \multicolumn{3}{|c|}{$I H C p 53$} \\
\hline & $n$ & Mean & $S D$ & Range & + & - & Error \\
\hline All stage I tumours & 50 & 18 & 15 & $0-65$ & 24 & 24 & 2 \\
\hline Local recurrence & 10 & 29 & 19 & $2-65$ & 4 & 6 & \\
\hline Regional recurrence & 13 & 19 & 13 & $3-45$ & 9 & 3 & 1 \\
\hline No recurrence & 27 & 14 & 12 & $0-43$ & 11 & 15 & 1 \\
\hline Advanced tumours & 37 & 24 & 16 & $0-58$ & 19 & 16 & 2 \\
\hline
\end{tabular}

Stage I tongue carcinomas $(n=50)$ and the group of advanced (stages II-IV) carcinomas $(n=37)$.

higher $\% 5 c E R$ than non-recurrent tumours $(\mathrm{p}=0.021 ; \mathrm{n}=50 ;$ Student's $t$ test $)$. This difference was a result primarily of the locally recurring tumours $(\mathrm{p}=0.012 ; \mathrm{n}=50$; Student's $t$ test).

Compared with stage I carcinomas, stage II-IV carcinomas tended to show a more pronounced DNA aberration expressed as $\% 5 \mathrm{cER}$ ( $\mathrm{p}=0.079$; Student's $t$ test).

However, stage I carcinomas with subsequent recurrence displayed DNA values comparable to the values of the stage II-IV carcinomas ( $\mathrm{p}=0.868$; Student's $t$ test).

p53 IMMUNOHISTOCHEMISTRY

Twenty four of 54 (with two immunohistochemical technical errors) stage I carcinomas and 19 of 35 stage II-IV carcinomas (with two immunohistochemical technical errors) showed p53 positive staining (table 1). The stage I carcinomas that developed regional recurrence were more often $\mathrm{p} 53$ positive than stage I carcinomas without regional recurrence ( $\mathrm{p}=0.046 ; \mathrm{n}=50 ; / \chi^{2}$ test $)$.

\section{NUCLEAR DNA CONTENT AND p53}

IMMUNOSTAINING

There were no differences in DNA aberration between p53 positive and p53 negative lesions either for stage I or stage II-IV tumours (Student's $t$ test) (table 1).

To evaluate whether nuclear DNA content or p53 immunostaining could have altered as a

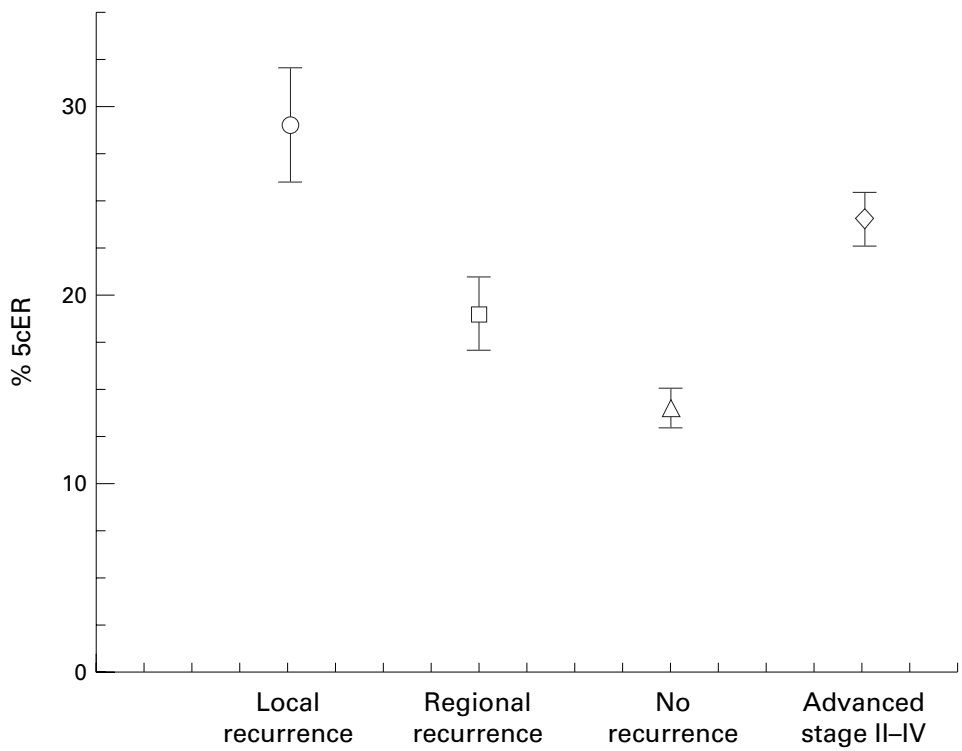

Figure 2 Means and standard error of means for stage I tongue carcinomas with (local recurrence, $n=10$; regional recurrence, $n=13)$ or without recurring disease $(n=31)$, and for advanced (stage II-IV) carcinomas $(n=37)$.
Table 2 Stage and differentiation

\begin{tabular}{lllll}
\hline Stage & $n$ & Well & Moderate & Poor \\
\hline I & 54 & 28 & 22 & 4 \\
II & 13 & 4 & 6 & 3 \\
III & 13 & 2 & 9 & 2 \\
IV & 11 & 2 & 5 & 4 \\
\hline \multirow{5}{*}{ Table 3 } & Results of statistical analyses & \\
\hline Analysis & Factor & RH & CI & p value \\
& \% & & & \\
B & \%5cER & 1.04 & $1.01-1.07$ & 0.020 \\
& Differentiation & 1.04 & $1.00-1.07$ & 0.032 \\
C & p53 & 1.05 & $0.20-3.11$ & 0.737 \\
& \%5cER & 1.01 & $0.97-1.04$ & 0.936 \\
& Differentiation & 0.84 & $0.25-2.76$ & 0.703 \\
& p53 & 0.28 & $0.07-1.08$ & 0.065 \\
\hline
\end{tabular}

Analysis A, Cox regression analysis of $\% 5 \mathrm{cER} v$ time to local recurrence. Analysis B, Cox multivariate regression analysis of $\% 5 \mathrm{cER}$, differentiation (well, 1 ; moderate/poor, 0 ), and p53 immunostaining (p53+, $1 ; \mathrm{p} 53-, 0) v$ time to local recurrence. Analysis C, Cox multivariate regression analysis of $\% 5 \mathrm{cER}$, differentiation, and $\mathrm{p} 53$ immunostaining (same coding) $v$ time to regional recurrence.

$\mathrm{RH}$, relative hazard; CI, 95\% confidence interval.

result of the age of the specimens, the first 14 and the last 15 specimens were compared and no differences were found.

TUMOUR DIFFERENTIATION AND RECURRENCE

Table 2 gives detail of tumour stages and differentiation. All tumour specimens had been graded into well, moderately, or poorly differentiated. ${ }^{17}$ More than half the stage I carcinomas were well differentiated, whereas less than a quarter of stage II-IV tumours were well differentiated ( $\mathrm{p}=0.007 ; \mathrm{n}=54 ; \chi^{2}$ test).

Among the stage II-IV tumours, the more advanced tumours dominated, and there were almost twice as many stage III-IV tumours as there were stage II tumours.

Among stage I carcinomas with local recurrence, six of 10 were well differentiated tumours, whereas carcinomas with regional recurrence were moderately or poorly differentiated (eight of 13). However, the differentiation of tumours with local or regional recurrence was not significantly different to that of non-recurrent carcinomas.

\section{TIME TO RECURRENCE}

Time to recurrence was defined as the time from diagnosis to when a recurring tumour was verified through a biopsy (months). Table 3 and fig 3 show times of recurrence.

The mean time to any kind of recurrence (local or regional) was 20 months (range, 3-56). For local recurrence the mean was 30 months (range, 11-56), and for regional recurrence the mean was 12 months (range, 3-40).

Statistical comparisons of the recurrence rate for tumours with different results of $\mathrm{p} 53$ immunostaining (+/-) and grade of differentiation (poor, moderate, well), respectively, were made using the Log Rank test $(n=54)$.

There was a significant difference in the risk for regional recurrence depending on p53 immunostaining ( $\mathrm{p}=0.036$ ) (fig 3 ) but no significance for grade of differentiation $(\mathrm{p}=0.359)$. 


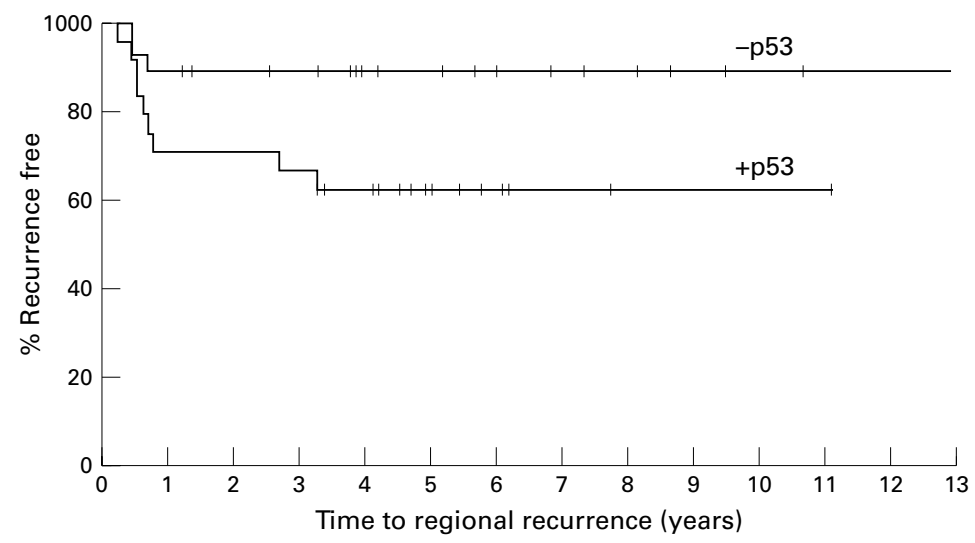

Figure 3 Percent patients free of regional recurrence against time to regional recurrence. Patients whose tumours were immunohistochemically positive $(+p 53) v$ patients whose tumours were immunohistochemically negative ( $p=0.036 ;$ Log Rank test).

p53 immunostaining or grade of differentiation were not significantly different for local or any (local or regional) recurrence.

For evaluation of $\% 5 c E R$ and recurrence, Cox regression analysis was performed ( $\mathrm{n}=54$ ).

Results were significant for local recurrence $(\mathrm{p}=0.020)$ (table 3$)$, and for local or regional recurrence $(p=0.053)$, but were not significant for regional recurrence.

Finally, Cox multivariate regression analysis was used to weigh the impact of the parameters: $\% 5 \mathrm{cER}$, grade of differentiation, and p53 immunostaining on recurrence $(n=54)$.

For local recurrence, $\% 5 c E R$ was significant $(\mathrm{p}=0.032)($ table 3$)$

For regional recurrence, only p53 immunostaining was close to significance $(\mathrm{p}=0.065)$ (table 3).

For local or regional recurrence, only $\% 5 \mathrm{cER}$ showed a borderline significance $(\mathrm{p}=0.066)$.

\section{SURVIVAL}

Ten of 54 patients died from disease during the follow up time. Comparisons of survival according to the grade of differentiation and p53 immunostaining were performed, using the Log Rank test. None of the variables had any significant impact on survival. Cox regression analysis showed no significance between evaluation of $\% 5 \mathrm{cER}$ and survival.

\section{Discussion}

Our study shows that image cytometry DNA analysis and p53 immunostaining in stage I tongue cancer can be useful in predicting the risk of recurrence. Tumours that recurred locally had a significantly higher degree of DNA deviation compared with tumours without local recurrence, and carcinomas that developed regional recurrence were more often p53 immunoreactive. Our study also shows that more aggressive tumours had a DNA content comparable to the more advanced (stages II-IV) carcinomas. Conventional histopathological grading of differentiation was not useful for evaluating the aggressiveness of stage I tongue carcinomas, but by adding "molecular" parameters, a more precise or "biological" classification of carcinomas might be possible.
When a limited tongue carcinoma recurs locally after surgery, the margins are always questioned. All specimens that were included showed free margins. However, the severe DNA deviation in the locally recurring tumours could indicate that the tumour, as well as the local recurrence, grew from a mucosa with precancerous features at a molecular level, undetectable by the microscope. These carcinomas could have developed as a result of "field cancerisation" rather than from insufficient margins. ${ }^{18}$ Genetic alterations in histologically normal mucosa from patients harbouring oral carcinomas have been demonstrated previously. ${ }^{19}$

Our results showed that overexpression of the p53 protein correlated with the risk of development of a regional recurrence. The p53 gene is activated in response to DNA damage. The wild-type p53 protein interacts with the WAF1 gene, which regulates the cell cycle via its protein (p21) inhibiting the cyclin-cyclin dependant kinase systems. The tumour suppressor function of $\mathrm{p} 53$ works in the $\mathrm{G} 1$ phase of the cell cycle, allowing time for control of DNA structure and repair. p53 might also induce cell death by apoptosis. Thus, an immortalised cell clone that has lost p53 tumour suppressor function could possess growth advantages leading to (early) spread of tumour cells and, as a result, regional recurrence. Alterations of the p53 gene are considered to be an early event in the development of squamous cell carcinomas and could be a prerequisite for the survival of tumour cells with severe DNA aberrations. No correlation between the degree of DNA deviation and immunohistochemical p53 staining was found because p 53 overexpression detected by immunohistochemistry does not always reflect mutations of the p53 gene. ${ }^{2021}$ However, further studies of the genetic alterations in our specimens would be of great interest.

In earlier investigations, Gluckman et al found that $\mathrm{p} 53$ positive $\mathrm{T} 1$ carcinomas of the oral cavity had a more aggressive course and a worse prognosis than p 53 negative tumours. ${ }^{22}$ Leedy et al, however, found no correlation between the presence of p53 overexpression and neck nodal metastasis. ${ }^{23}$

Over the years, numerous studies have shown varying results on the prognostic value of DNA and p53 analysis for head and neck cancer. The differences might be because of variations in methodologies and the selection of patients. In many reports, tumours from different sites and of various sizes ( $\mathrm{T}$ and $\mathrm{N}$ categories) were included. ${ }^{78}{ }^{10-13}$ The anatomical origin of a tumour plays a role in its development, its possibility to progress, and the risk of (occult) metastasis. ${ }^{24}$ Thus, the diversity of sites in the relatively small series of head and neck cancers presented over the years has probably influenced the results of the studies on biological markers for these tumours.

Depending on tumour stage, biological parameters might play different roles because the more advanced tumours have a more pronounced heterogeneity among their cells, their genetic equipment, and their subsequent 
characteristics. A carcinoma might develop by clonal expansion from one, genetically fragile cell. Because of this fragility, further mutations or genetic alterations take place, leading to the development of cell clones with features different from the initial clone. ${ }^{25}$ Thus, biological characteristics measured in a single sample from a small tumour are more likely to be representative in terms of mirroring the aggressiveness of the tumour than a sample from an extended tumour, where other parts of the tumour containing other clones could have considerably different biological properties. ${ }^{26}$

None of the parameters studied affected survival. Ten of the 23 patients who developed a recurrence succumbed to the disease. Thus, even when the tumours showed their aggressiveness by recurring, many patients could still be cured. However, the numbers studied were too small for further conclusions concerning the influence of the parameters on survival, especially because there were large differences in the treatment of recurring tumours depending on the site of recurrence, the performance status of the patients, and the local treatment traditions of different hospitals.

Our study indicates that for patients harbouring a stage I tongue carcinoma with a high degree of DNA deviation, generous safe margins should be allowed when local surgical excision is performed to avoid local recurrence. Furthermore, at least in patients with tumours exhibiting p53 overexpression, adjuvant treatment of the neck should be considered.

This work was supported by grants from Cancerfonden (2992B94-04xBC), Cancerföreningen i Stockholm and the Swedish Society of Medicine. We wish to thank Ms A-B Wikström for valuable technical assistance and Mr B Nilsson, Department of Cancer Epidemiology, Radiumhemmet, Karolinska Hospital, for help with statistical interpretations.

1 Biörklund A, Anderson H, Möller T, et al. Carcinoma of the tongue in young adults. Clin Otolaryngol 1995;20:186.

2 Nathansson A, Agren K, Biörklund A, et al. Evaluation of some prognostic factors in small squamous cell carcinoma of the mobile tongue: a multicenter study in Sweden. Head Neck 1989;11:387-92.

3 Odell EW, Piyush J, Sherriff M, et al. The prognostic value of individual histologic grading parameters in small lingual of individual histologic grading parameters in small lingual squamous cell carcinomas. The import
of invasion. Cancer 1994;74:789-94.

4 Gomez R, El-Naggar AK, Byers RM, et al. Squamous carcinoma of oral tongue: prognostic significance of flowcytometric DNA content. Mod Pathol 1992;5:141-5.
5 Cooke LD, Cooke TG, Forster G, et al. Flow cytometric Cooke LD, Cooke TG, Forster G, et al. Flow cytometric nalysis of DNA content in squamous carcinoma of the ongue: the relationship to host and tumour factors and survival. Clin Otolaryngol 1994;19:131-4.

6 Saito T, Sato J, Satoh A, et al. Flow cytometric analysis of nuclear DNA content in tongue squamous cell carcinoma: relation to cervical lymph node metastasis. Int $\mathcal{F}$ Oral Maxillofac Surg 1994;23:28-31.

7 Högmo A, Munck-Wikland E, Kuylenstierna R, et al. Nuclear DNA content and p53 immunostaining in oral squamous cell carcinoma - an analysis of a consecutive 10-year material. Int f Oncol 1994;5:915-20.

8 Zätterström U, Wennerberg J, Ewers SB, et al. Prognostic factors in head and neck cancer: histologic grading, DNA ploidy and nodal status. Head Neck 1991;13:477-87.

9 Munck-Wikland E, Kuylenstierna R, Lind M, et al. The prognostic value of cytometric DNA analysis in early stage prognostic value of cytometric D Cancer 1992;28B:135-8.

10 Field JK, Spandidos DA, Malliri A, et al. Elevated p53 expression correlates with a history of heavy smoking in
squamous cell carcinoma of the head and neck. Brf Cancer 1991;64:573-7.

11 Watling D, Gown A, Coltrera M. Overexpression of p53 in head and neck cancer. Head Neck 1992;14:437-44.

12 Langdon J, Partridge M. Expression of the tumour suppressor gene p53 in oral cancer. BrF Oral Maxillofac Surg 1992; 30:214-20.

13 Shin D, Lee JS, Lippman S, et al. p53 expression: predicting recurrence and secondary primary tumours in head and neck squamous cell carcinoma. F Natl Cancer Inst 1996;88: 519-29

14 Bischoff JR, Kirn DH, Willliams A, et al. An adenovirus mutant that replicates selectively in p53-deficient human tumour cells. Science 1996;274:373-6.

15 Auer G, Askensten U, Ahrens O. Cytophotometry. Hum Pathol 1989;20:518-27.

16 Munck-Wikland E, Rubio CA, Auer G, et al. Control cells for image cytometric DNA analysis of esophageal tissue and the influence of preopretaive treatment. Anal Quant Cytol Histol 1990;12:267-74.

17 Broders A. The microscopic grading of cancer. Surg Clin North Am 1941;21:947-62.

18 Slaughter DP, Southwick HW, Smejkal W. "Field cancerization" in oral stratified squamous epithelium. Cancer 1953;6:963-8

19 Munck-Wikland E, Blegen H, Lewensohn-Fuchs I, et al. p53 overexpression in normal and dysplastic tissues adjacent to p53 negative squamous cell carcinomas of the head and neck. Int $\mathcal{F}$ Oncol 1997;11:97-104.

$20 \mathrm{Xu} \mathrm{L}$, Chen Y-T, Huvos A, et al. Overexpression of $\mathrm{p} 53$ protein in squamous cell carcinomas of the head and neck without apparent gene mutations. Diagn Mol Pathol without apparen

21 Nylander K, Nilsson P, Mehle C, et al. p53 mutations, protein expression and cell proliferation in squamous cell carinomas of the head and neck. Br f Cancer 1995;71:826 30.

22 Gluckman JL, Stambrook PJ, Pavelic ZP. Prognostic significance of p53 protein accumulation in early stage $\mathrm{T} 1$ oral cavity cancer. Oral Oncol Eur $\mathcal{F}$ Cancer 1994;30B:281.

23 Leedy DA, Trune DR, Kronz JD, et al. Tumour angiogenesis, the p53 antigen, and cervical metastasis in squamous cell carcinoma of the tongue. Otolaryngol Head Neck Surg 1994;111:417-22.

24 Lindberg R. Distribution of cervical lymph node metastases from squamous cell carcinoma of the upper respiratory and digestive tracts. Cancer 1972;29:1446-9.

25 Nowell PC. The clonal evolution of tumour cell populations. Science 1976;194:23-8.

26 El-Naggar AK, Lopez-Varela V, Luna MA, et al. Intratumoural DNA content heterogeneity in laryngeal squamous cell carcinoma. Arch Otolaryngol Head Neck Surg 1992;118: 169-73. 